A qualidade do saneamento ambiental no Assentamento Rural Amparo no município de Dourados-MS

Heloiza Cristina Holgado-Silva, Juliana Benites Padua, Leandro Renne Camilo, Tathiane Marques Dorneles

\title{
A QUALIDADE DO SANEAMENTO AMBIENTAL NO ASSENTAMENTO RURAL AMPARO NO MUNICÍPIO DE DOURADOS-MS
}

The quality of environmental sanitation in rural settlement Amparo in Dourados-MS (Brazil)

Heloiza Cristina Holgado-Silva

Universidade Estadual de Mato Grosso do Sul, Dourados, Mato Grosso do Sul, Brasil heloizaholgado@hotmail.com

Juliana Benites Padua

Universidade Federal da Grande Dourados, Dourados, Mato Grosso do Sul, Brasil julianabenitespadua@gmail.com

Leandro Renne Camilo

Universidade Federal da Grande Dourados, Dourados, Mato Grosso do Sul, Brasil leandrorenne@hotmail.com

Tathiane Marques Dorneles Universidade Estadual de Mato Grosso do Sul, Ponta Porã, Mato Grosso do Sul, Brasil tathmd@gmail.com

Artigo recebido em 27/06/2013 e aceito para publicação em 08/01/2014

RESUMO: O saneamento ambiental representa um importante instrumento no combate à proliferação de doenças. Sendo a qualidade ambiental imprescindível ao bem-estar e a saúde humana. Esta pesquisa pretende evidenciar a atual estrutura sanitária do Assentamento Amparo, ressaltando a possibilidade de contaminação do solo e da água, mediante o auxílio de entrevista semiestruturada. Os resultados indicaram que não existem instalações de saneamento ambiental para tratamento do esgoto doméstico e coleta de lixo. Assim, os moradores realizam predominantemente o descarte do esgoto doméstico em fossas negras e a queima dos resíduos sólidos (lixo). Observou-se que 100\% dos domicílios contam com canalização interna e que são abastecidos com água de um poço artesiano comunitário. Em relação à percepção sobre questões ambientais, os resultados encontram-se díspares, pois $60 \%$ relatam problemas, enquanto $40 \%$ não sabem informar ou não visualizam problemas. Os resultados da pesquisa demonstram a necessidade de medidas que venham a conscientizar os moradores sobre práticas prejudicais ao meio ambiente, e consequentemente ao seu próprio bem-estar, bem como a relevância de se implantar estruturas de saneamento ambiental adequadas.

Palavras-chave: Saneamento Ambiental; Qualidade Ambiental; Assentamento Rural.

ABSTRACT: Environmental sanitation is an important tool in combating the proliferation diseases. The environmental quality is essential to the welfare and human health. This research aims to verify the current sanitation systems of the Settlement Amparo, emphasizing the possibility of contamination of soil and water. So were used semi-structured interviews. The results indicated that there aren't installations for the sanitary sewage treatment and garbage collection. The habitants predominantly depositing the sanitary sewage in 
rudimental cesspools and the burning of solid waste. Thus, was observed that $100 \%$ of households have internal canalization and are supplied with water from artesian well community. Regarding perception of Environmental subjects, the results are disparate, $60 \%$ reported problems, while $40 \%$ didn't know or didn't visualize problems. Data in this research show the need the to awareness households about harmful practices to the environment and to their own well-being, as well as the importance of sanitation systems appropriate.

Key words: Environmental Sanitation; Environmental Quality; Rural Settlement.

\section{INTRODUÇÃO}

As diretrizes nacionais e a política federal de saneamento básico determina que um dos objetivos da Política Federal de Saneamento Básico é proporcionar condições adequadas de salubridade ambiental às populações rurais (BRASIL, 2007). De acordo com Batista e Silva (2006) o conceito de salubridade ambiental compreende diversos elementos do saneamento ambiental. A falta de salubridade ambiental, ou seja, da qualidade ambiental, está diretamente relacionada à falta de infra-estrutura sanitária, como por exemplo, rede de esgoto e disponibilidade de água potável.

Desta forma, o saneamento ambiental é o conjunto de ações socioeconômicas que visa obter a salubridade ambiental, essencial para a proteção e melhoria das condições de vida da população tanto urbana quanto rural (BRASIL, 2006). Tais ações são expressas por meio do "[...] abastecimento de água potável, coleta e disposição sanitária de resíduos sólidos, líquidos e gasosos, promoção da disciplina sanitária de uso do solo, drenagem urbana, controle de doenças transmissíveis e demais serviços e obras especializadas" (BRASIL, 2006, p.14).

Verifica-se que o saneamento ambiental está relacionado sobremaneira com o modo de utilização e ocupação do espaço, este por sua vez é configurado por aspectos subjetivos referentes aos interesses dos que detém a posse do território. Embora tais modos sejam regulados em lei e estabelecidos em sociedade, nem sempre a realidade demonstra andar consoante, como se verificou no histórico da questão agrária no Brasil (FERRETE et al, 2008).

Lopes, Borges e Lopes (2012), salientam que os recursos naturais empregados na produção agrícola, com destaque para a água e o solo, devem indicar satisfatórios estados de sustentabilidade para somente depois serem utilizados nas culturas. Ainda segundo os autores, é nesse ponto em que se insere o saneamento ambiental e sua importância.

Nessa perspectiva a política agrícola apresenta seus fundamentos, sendo que o "processo de desenvolvimento agrícola deve proporcionar ao homem do campo o acesso aos serviços essenciais: saúde, educação, segurança pública, transporte, eletrificação, comunicação, habitação, saneamento, lazer e outros benefícios sociais" (BRASIL, 1991, p. 1). Ademais estabelece que o Poder Público deva implantar obras que tenham como objetivo o bem-estar social de comunidades rurais, dentre estas cita-se investimentos em saneamento básico (BRASIL,1991).

Em relação às atividades de saneamento no Brasil, Daltro Filho e Santos (2001a, p. 2) destaca que estas " $[. .$.$] tem sido mais sentida nos centros$ urbanos. Muito pouco tem sido feito de saneamento no meio rural".

De acordo com o censo demográfico 2010 a população residente na área rural brasileira é de 29.830.007 habitantes, distribuídos em 8.097.418 domicílios. A Figura 1 apresenta o crescimento dos índices percentuais de domicílios rurais com serviço de coleta de lixo, com rede geral de esgoto e fossa séptica e com rede geral de abastecimento de água, em todas as regiões brasileiras.

Com referência a domicílios em áreas rurais com coleta de lixo, observou-se uma ampliação do serviço no Brasil de 13,6 pontos percentuais, quando comparado o período de 2000 a 2010, já a região Centro-Oeste apresentou-se como a quarta em maior percentual, superada respectivamente pelas regiões Sul, Sudeste e Nordeste. No tocante a esgotamento sanitário observou-se que a proporção de domicílios com rede geral de esgoto e fossa séptica no Centro-Oeste em 2000 era de 6,0\% e em 2010 de 12,7\%, perfazendo um aumento de 6,7 pontos percentuais, representando o segundo maior acréscimo entre as 
regiões brasileiras. Em relação a domicílios rurais ligados à rede geral de abastecimento de água verificou-se que na região Centro-Oeste houve crescimento de 4,3 pontos percentuais no período de 2000 a 2010 , sendo superado respectivamente pelo Nordeste, Sul e Norte (BRASIL, 2011).

Figura 1. Aumento em pontos percentuais da quantidade de domicílios rurais atendidos pelos serviços de coleta de lixo, rede geral de esgoto e fossa séptica e ligados à rede geral de abastecimento de água, no período de 2000 a 2010.

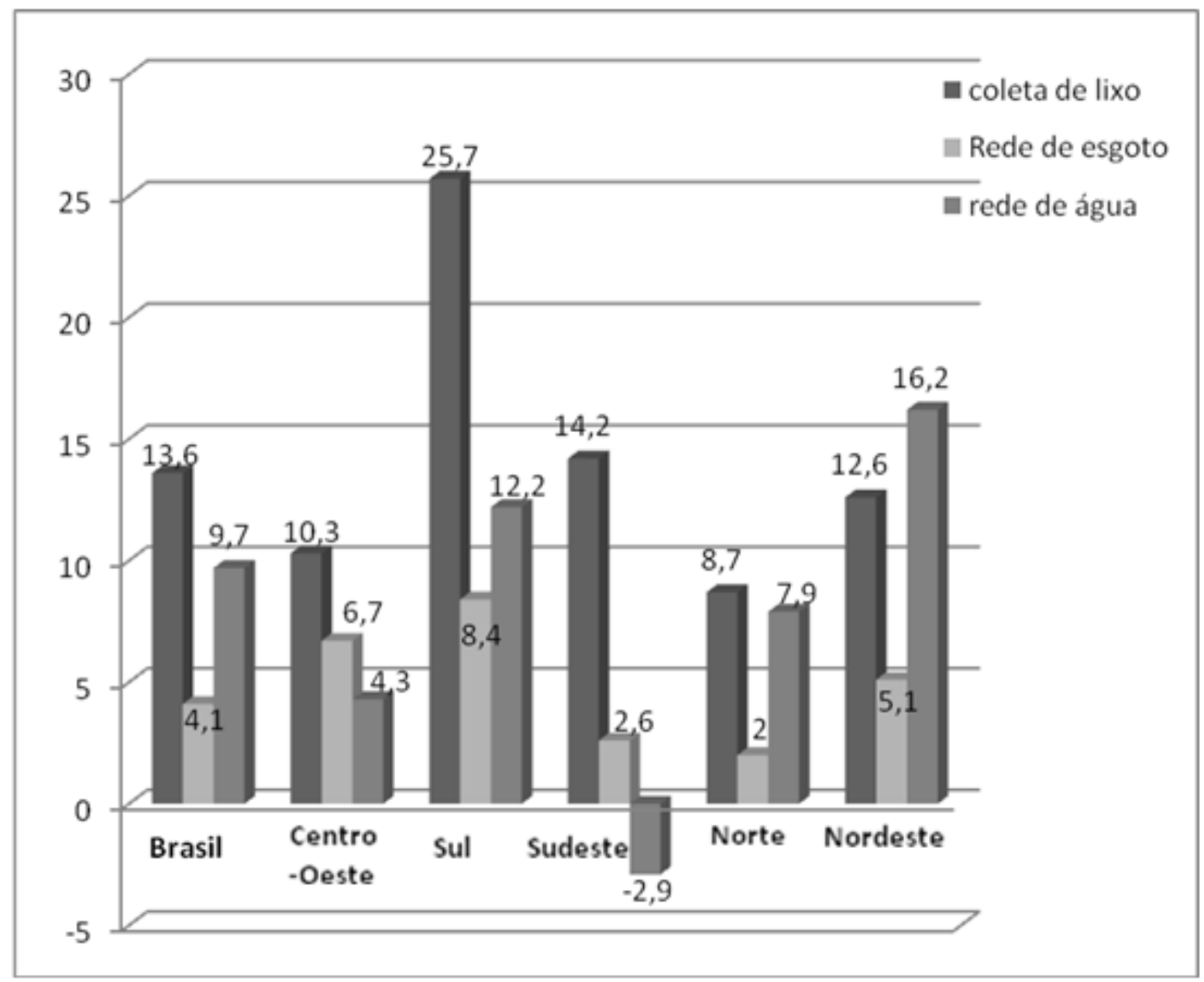

Fonte: IBGE (Censo demográfico 2000/2010). Org. dos autores.

O censo demográfico 2010 pesquisou a adequação do tipo de saneamento nos estados brasileiros. Sendo que os tipos de saneamento foram classificados em adequado, semi-adequado e inadequado. Adequado refere-se aos domicílios com acesso a serviços de rede geral de abastecimento de água, esgotamento sanitário por rede geral ou fossa séptica e coleta de lixo. Já os semi-adequados são domicílios que possuem pelo menos uma forma de saneamento considerada adequada, enquanto que o inadequado abrange todas as formas de saneamento consideradas não adequadas (BRASIL, 2011).

Desta forma, observa-se que o estado de Mato Grosso do Sul possui somente 1,1\% de seus domicílios rurais com saneamento considerado adequado, enquanto que $65,3 \%$ apresentam-se de forma inadequada (Figura 2). 
Figura 2. Percentual de domicílios rurais particulares por tipo de saneamento em 2010.

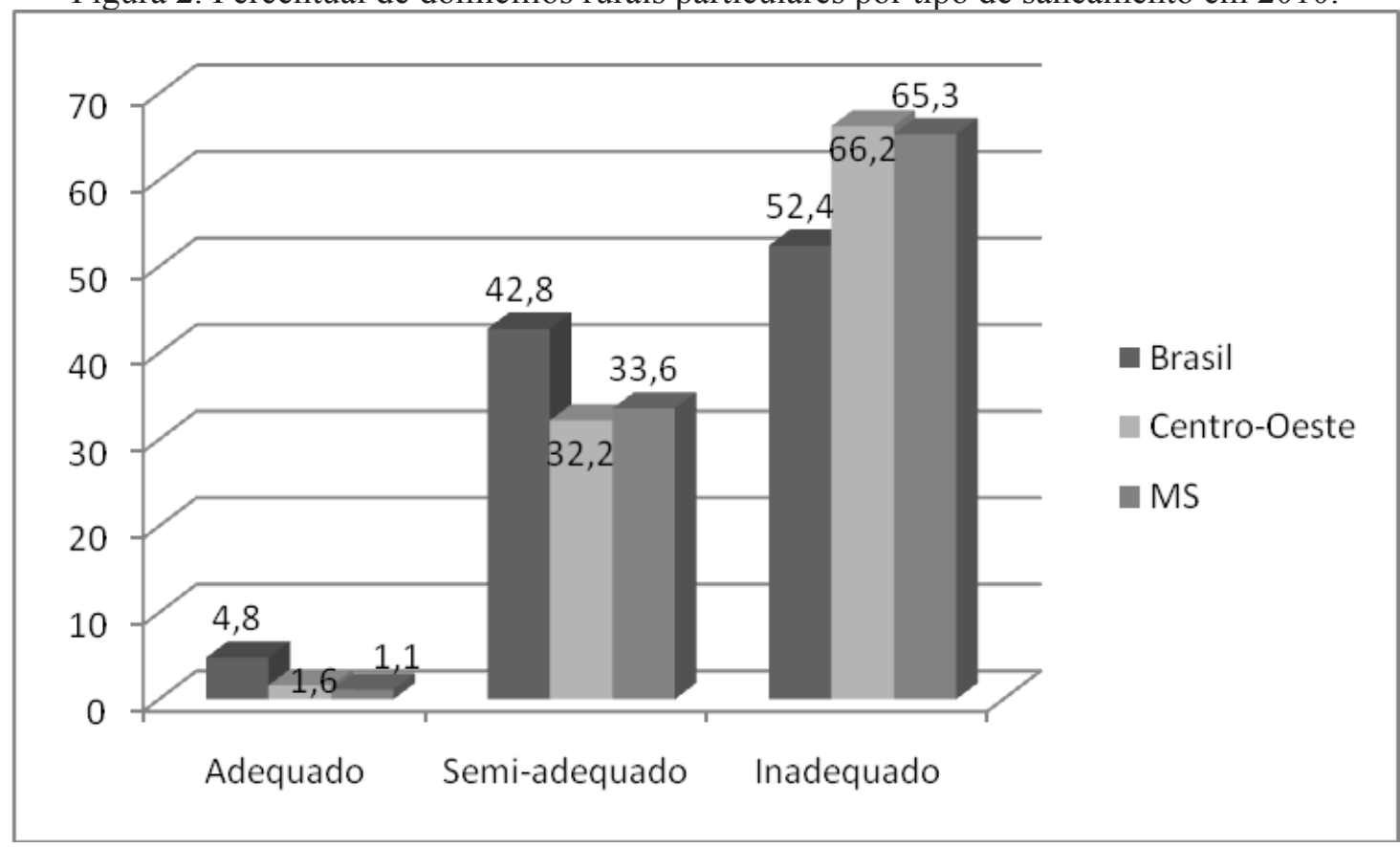

Fonte: IBGE (Censo demográfico 2000/2010). Org. dos autores.

Em relação ao município de Dourados/MS este possui um índice de atendimento da rede de abastecimento de água de aproximadamente $90 \%$ da população urbana, já a rede de esgoto beneficia somente $25 \%$ da população (IORIO et al., 2009). Vale destacar que em termos populacionais a cidade de Dourados é a segunda maior do estado e possui uma população de 196.035 habitantes (IBGE, 2014).

De acordo com Brasil (2011) o esgotamento sanitário é o que representa o maior desafio com vistas a alcançar índices satisfatórios, que permitam assegurar melhores condições de vida à população e preservação da qualidade ambiental.

Os entraves tecnológicos, políticos e gerenciais tornam difícil a propagação de benefícios referentes a saneamento à população rural, bem como a cidades de pequeno porte. Tais empecilhos devem ser superados para que se possa utilizar o saneamento com um meio promotor da saúde. Desta forma, o saneamento ambiental deve enfatizar o desenvolvimento sustentável, permitindo a conservação da biodiversidade e do bem-estar da população (BRASIL, 2006).

De acordo com Ferrete et al. (2007) a ausência de saneamento ambiental tem sido apontada como um elemento que contribui para a presença de doenças na população mundial, sobretudo as propagadas por meio da água. Pesquisadores comprometidos com as temáticas de saneamento ambiental tem se preocupado com o destino final dos resíduos, que quando realizada de forma incorreta pode ocasionar o risco de contaminação (MOSCARDI; NOBRE, 2012). Enfatiza-se que os resíduos podem conter substâncias tóxicas ou agentes patogênicos, que contaminam o solo e água superficial ou subterrânea, o que resulta em uma limitação do seu uso (FERRETE et al., 2007).

Conhecer as condições de vida e a qualidade do saneamento nas áreas rurais auxilia no diagnóstico da realidade no campo, o que subsidia a formulação de políticas públicas que promovam melhorias para a população e promovam a conservação dos recursos naturais. Diante do exposto, essa pesquisa pretende realizar um estudo exploratório no Assentamento Amparo, abordando alguns aspectos de sua atual estrutura sanitária ambiental, identificando possíveis riscos de contaminação de solo e da água.

\section{MATERIAL E MÉTODOS}

O objeto empírico desse estudo é o Assentamento Amparo, assentamento federal em terras 
desapropriadas, criado em 22 de dezembro de 1997, localizado no Distrito de Itahum, município de Dourados, estado de Mato Grosso do Sul. O assentamento situa-se a aproximadamente $300 \mathrm{~km}$ da capital Campo Grande, $65 \mathrm{~km}$ de Dourados e $15 \mathrm{~km}$ do Distrito, com latitude de $22^{\circ} 10^{\prime}$ e longitude de $53^{\circ} 20^{\prime}$ (AGRAER, 1997). Possui 67 famílias assentadas e área total de $1.126,8933$ hectares, dos quais $1.102,8391$ hectares equivalem à soma das áreas dos 67 lotes (20\% é destinado a Reserva Legal), 2,9998 hectares se referem ao centro rural e 21,0544 hectares a estradas vicinais (INCRA, 2012). As áreas das parcelas variam de tamanho entre 15 a 29 hectares.
Na presente pesquisa optou por uma amostra de 27 lotes no assentamento, que é apresentada pelo intervalo demonstrado por setas largas na Figura 3. Foi preponderante para a escolha da amostra o fato desses lotes se situarem muito próximos ao rio Dourados e o Córrego Rego d'água, sendo essas as divisas naturais da área pertencente ao assentamento. O Rio Dourados abastece a cidade de Dourados/MS e é um dos principais afluentes da Bacia do Ivinhema. Essa bacia é formada por 25 municípios e atende cerca de $26 \%$ da população do estado de Mato Grosso do Sul (ERMENEGILDO et al., 2012). A população estimada do estado em 2013 era de 2.587.269 habitantes (IBGE, 2014).

Figura 3. Localização do Assentamento Amparo e indicação dos lotes que compõe a amostra (setas largas).

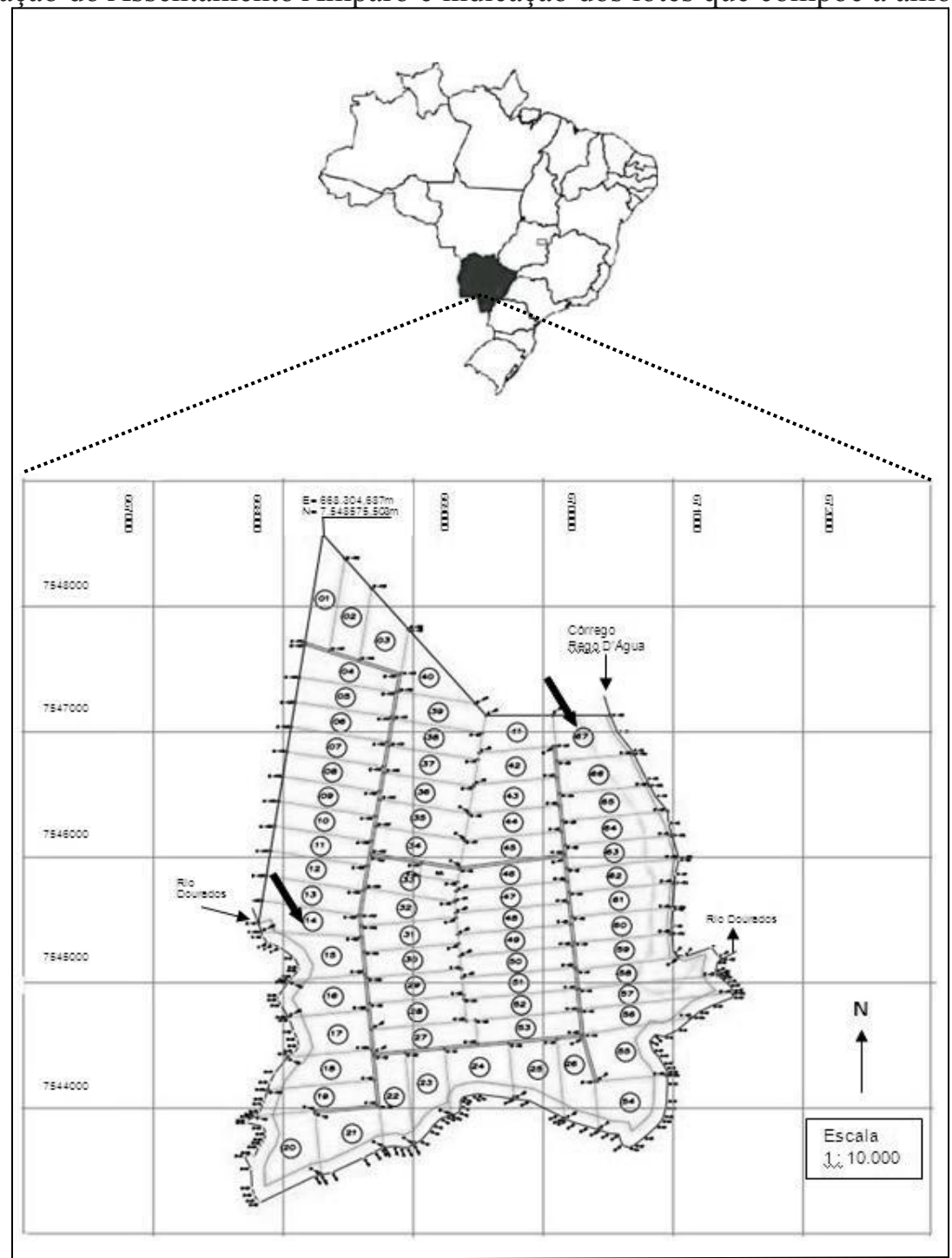

Fonte: Adaptado de INCRA (1997). 
Para a obtenção dos dados optou-se pela realização de uma entrevista semiestruturada, por meio de visitas aos lotes. Assim, o levantamento de dados foi aplicado pessoalmente junto a 10 entrevistados. Não foi possível entrevistar a totalidade da amostra devido ao fato dos assentados não estarem presentes em seus lotes no período da pesquisa de campo, decorrente de diversos fatores relatados pela vizinhança.

\section{RESULTADOS E DISCUSSÃO}

O Assentamento Amparo possui rede de energia elétrica, mas não conta com coleta de lixo pelo serviço público e nem de rede de tratamento de esgoto doméstico. Observou-se que todos os domicílios dos entrevistados possuem canalização interna. A origem da água deriva-se de um poço artesiano, sendo este um poço comunitário, que atende a todo o assentamento. Alguns entrevistados manifestaram preocupação quanto ao nível da água presente no poço e ao fato de poucas pessoas contribuírem financeiramente, de forma voluntária, com um valor destinando à manutenção e reparos eventuais dos equipamentos utilizados para a captação da água.

O esgoto doméstico é depositado por $90 \%$ dos entrevistados em fossas negras e 10\% deposita em um poço comum que já havia secado, como demonstrado na Figura 4. Somente um entrevistado afirmou que o esgoto proveniente da pia e do tanque é disposto a céu aberto, em direção ao pasto, ou seja, não tem a mesma destinação do esgoto sanitário.

Figura 4. Destinação do esgoto doméstico no assentamento.

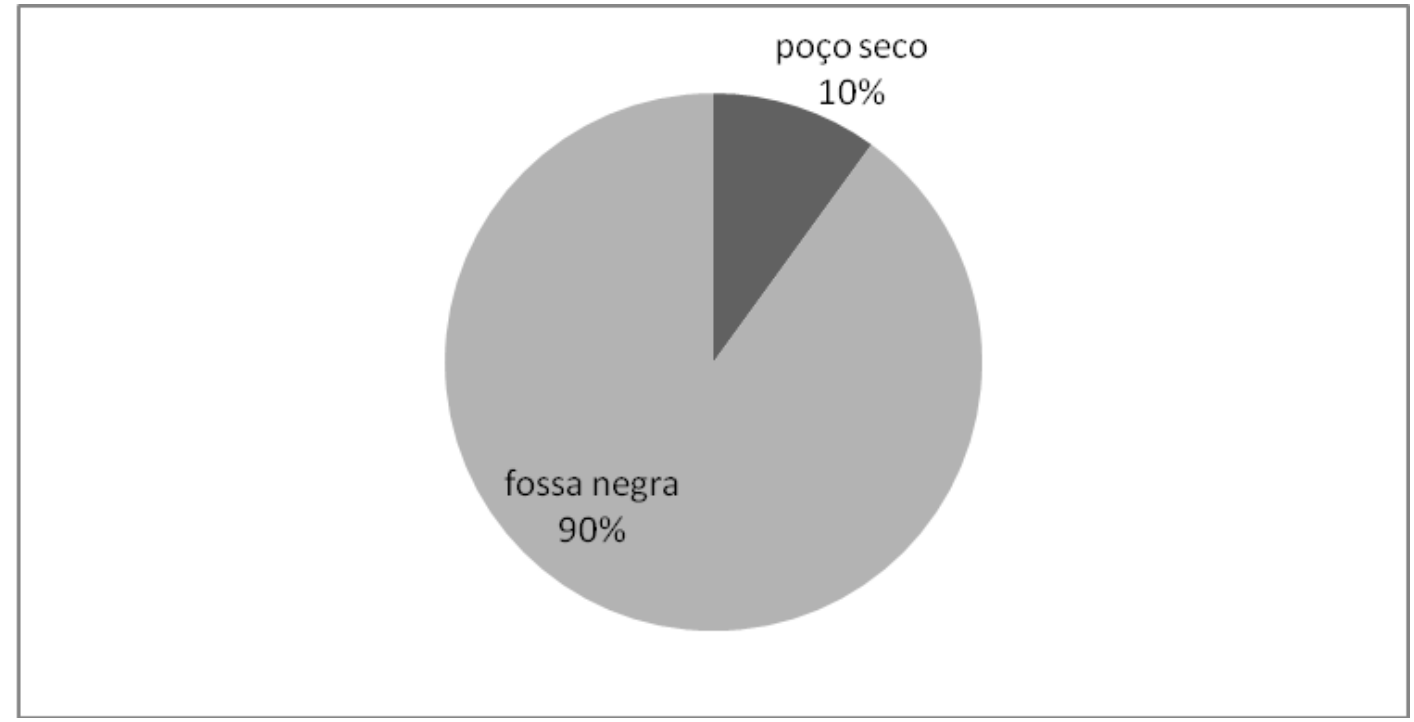

Fonte: Dados da pesquisa (2013). Org. dos autores.

O esgoto doméstico é constituído por “[...] água de banho, excretas, papel higiênico, restos de comida, sabão, detergentes e águas de lavagem" (BRASIL, 2006, p. 154), provenientes de residências, “[...] estabelecimentos comerciais, instituições ou quaisquer edificações que dispõe de instalações de banheiros, lavanderias e cozinhas" (BRASIL, 2006, p. 154).

O esgoto doméstico depositado no solo pode contaminar a água e também o próprio solo. Quando depositado a céu aberto o esgoto doméstico pode ser arrastado para os cursos d'água devido à ação da chuva. Em locais onde se encontram fossas negras existe o risco de contaminação com a elevação do lençol freático em períodos de chuva (FERRETE et al., 2007) .

É preocupante a falta de instalações de saneamento ambiental para tratamento do esgoto doméstico no Assentamento. Cita-se como uma alternativa individual capaz de eliminar o risco de contaminação do solo e da água, com o esgoto doméstico, a utilização de fossa séptica. No entanto, deve-se levar em conta 
o custo de sua implantação, se compatível com a realidade econômica dos assentados.

Daltro Filho e Santos (2001b) realizou pesquisa no Assentamento 8 de março, localizado a $35 \mathrm{~km}$ de Aracaju/Sergipe e descreve algumas soluções para a problemática do esgotamento doméstico na localidade. Uma solução seria a implantação de um sistema de disposição coletiva dos esgotos, o qual o autor chama de micro-sistemas, que são redes de esgotos setorizadas. Também cita a implantação do sistema convencional de disposição coletiva dos esgotos. Outra solução seria o tratamento de esgoto com um sistema de tratamento de casa a casa, onde em um local estrategicamente escolhido todo o tratamento realizar-se-ia.

Novaes et al. (2002) salientam a utilização de fossa séptica biodigestora com a finalidade de melhorar o saneamento rural, sendo um meio de substituição à fossas negras que contaminam às águas subterrâneas de poços comuns. Ainda abordam que os efluentes produtivos poderiam ser empregados como adubo orgânico, fomentando o desenvolvimento da agricultura orgânica.

No entanto, em tais soluções devem-se analisar as viabilidades, considerando a distância do Assentamento até a cidade de Dourados/MS, à distância até as redes de tratamento de esgoto já existentes, o custo financeiro de implantação, os benefícios ambientais e sociais, dentre outros aspectos.

A Figura 5 apresenta a destinação do lixo doméstico do assentamento, sendo que 90\% afirmaram queimá-lo e $10 \%$ jogam em um poço seco.

Figura 5. Destinação do lixo doméstico no Assentamento Amparo.

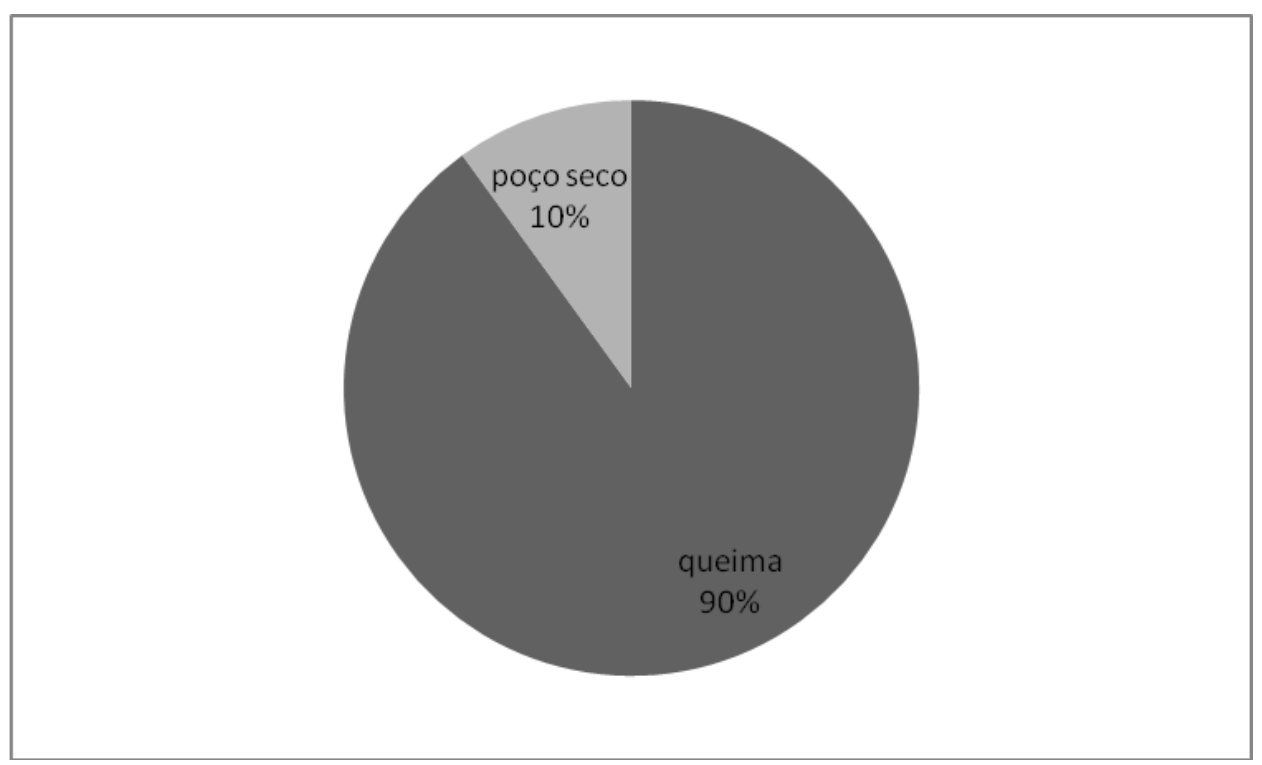

Fonte: Dados da pesquisa (2013). Org. dos autores.

O resultado da presente pesquisa está ao encontro dos resultados do censo demográfico do ano de 2010. Nesse, o alto custo e a dificuldade da coleta de lixo no meio rural permitiram que a queima fosse a destinação mais utilizada pelos moradores. Os percentuais demonstram que no ano de 2000, a opção por esse destino era de 48,2\% dos domicílios e em 2010 de $58,1 \%$. Enquanto que o descarte do lixo em terreno baldio sofreu um decréscimo, em 2000 era praticado por 20,8\% dos domicílios e em 2010 passou para $9,1 \%$ (BRASIL, 2011).

A destinação dos resíduos sólidos (lixo) é atualmente um dos problemas ambientais mais observados, sendo este agravado em decorrência da quantidade de plástico existente no lixo. Tal situação nos remete a necessidade do armazenamento e disposição corretos do lixo, inclusive em áreas rurais (DALTRO FILHO; SANTOS, 2001b). 
A prática da queima dos resíduos libera gases tóxicos, que podem provocar o aparecimento de doenças respiratórias e de pele. Salienta-se que, mesmo com a queima ainda não se consegue eliminar a totalidade dos resíduos sólidos (LOPES, BORGES; LOPES, 2012).

Conforme evidenciado na Figura 6 quando questionados sobre os principais problemas ambientais enfrentados no assentamento, $20 \%$ não souberam informar, outros $20 \%$ indicaram não observar problemas ambientais, enquanto que $60 \%$ relataram diversos problemas, sobretudo a erosão. Também se verificou respostas como a queima do capim braquiária, a pouca arborização, a queima do lixo doméstico e a preocupação com o nível da água do poço artesiano que abastece todo o assentamento.

A possibilidade de ocorrência da erosão envolve condições naturais e também os modelos de utilização da terra. A erosão reduz a fertilidade do solo, tendo em vista que com o solo mais denso e fino, as raízes das plantas passam a encontrar mais dificuldade em penetrar o solo, podendo se instalar superficialmente. Também se verifica a diminuição da retenção de água no solo e a perda de nutrientes. Nota-se, quando a erosão se apresenta de forma extrema, a deformação do terreno (ARAUJO; ALMEIDA; GUERRA, 2007).

Figura 6. Maiores problemas ambientais enfrentados no assentamento, segundo os entrevistados.

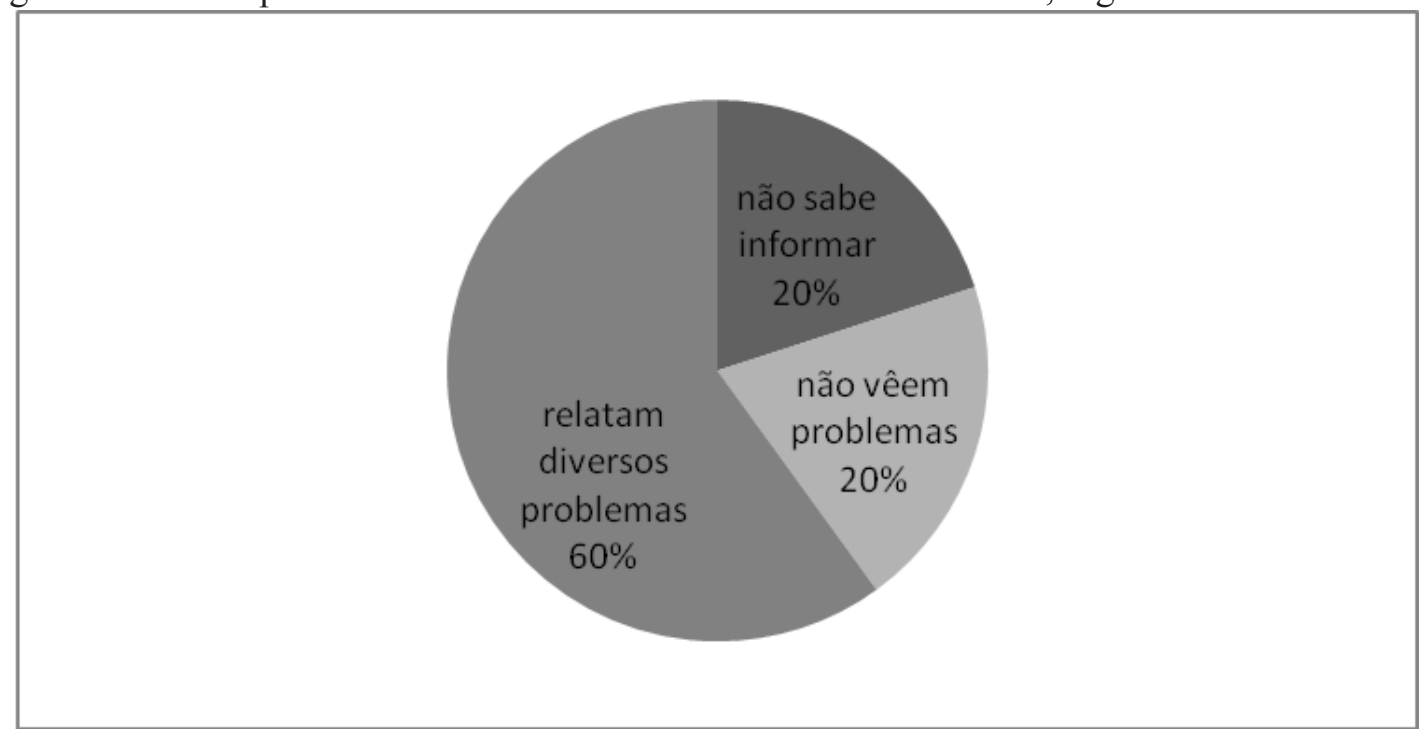

Fonte: Dados da pesquisa (2013). Org. dos autores.

Percebeu-se por parte dos entrevistados a preocupação com algumas práticas adotadas, visualizadas como potenciais interferências na qualidade do meio ambiente. Tal percepção denota conhecimentos relativos à importância da preservação dos recursos naturais, embora a prática de atitudes prejudiciais seja apontada a outros assentados, e não a si mesmos. Desta forma, observou-se que nem sempre as atitudes estão de acordo com o conhecimento adquirido, principalmente quando se leva em consideração o fato de que $90 \%$ dos moradores realizarem a queima do lixo. No entanto, essa prática representa a "única" solução viável observada pelos assentados.

Perguntados a respeito de como é discutida a questão ambiental no assentamento, a maioria afirmou que não há discussões sobre o tema, $30 \%$ declarou que existem reuniões na Associação do assentamento, $10 \%$ somente discutem o tema em casa e $10 \%$ não souberam informar (Figura 7). 
Figura 7: Formas de discussão da questão ambiental no assentamento.

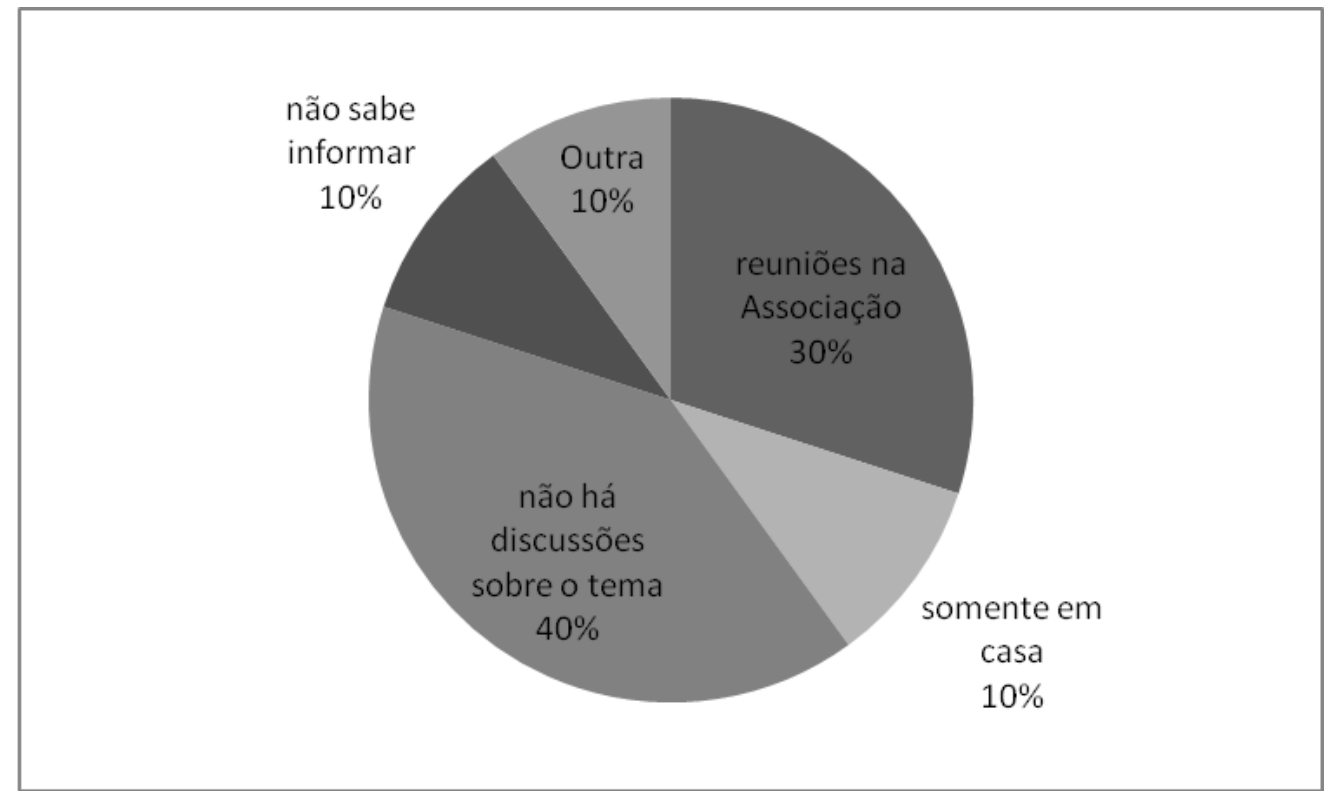

Fonte: Dados da pesquisa (2013). Org. dos autores.

Quando questionados em relação ao repasse de informações referentes à preservação ambiental, notou-se na Tabela 1 , que $50 \%$ afirmaram ter recebido orientações e outros $50 \%$ não. Aqueles que afirmaram positivamente relataram ter recebido orientações da
Comissão Pastoral da Terra (CPT) e da Prefeitura Municipal de Dourados, com destaque à informação sobre a utilização da água no assentamento.

Tabela 1: Percentual de repasse de orientações relativas à preservação ambiental.

\begin{tabular}{l|c|c}
\hline Questionamento & Sim & \multicolumn{2}{c}{ Não } \\
\hline $\begin{array}{l}\text { Algum órgão/pessoa já repassou orientações aos } \\
\text { assentados em relação à preservação ambiental }\end{array}$ & $50 \%$ & $50 \%$ \\
\hline
\end{tabular}

Fonte: Dados da pesquisa (2013). Org. dos autores.

A Figura 8 demonstra as respostas dos entrevistados quando perguntados se tinham alguma sugestão para a preservação ambiental no assentamento, $20 \%$ afirmaram não possuir sugestão alguma, outros $20 \%$ declararam "que está bom demais do jeito em que está", $30 \%$ relataram que deveria haver maior conscientização sobre a questão ambiental, os demais (30\% dos assentados) consideram que deveria ser oferecido um curso de manejo do solo e que o reflorestamento que está sendo realizado atualmente no assentamento deveria abranger os demais lotes. 
Figura 8: Sugestões para a preservação ambiental no assentamento.

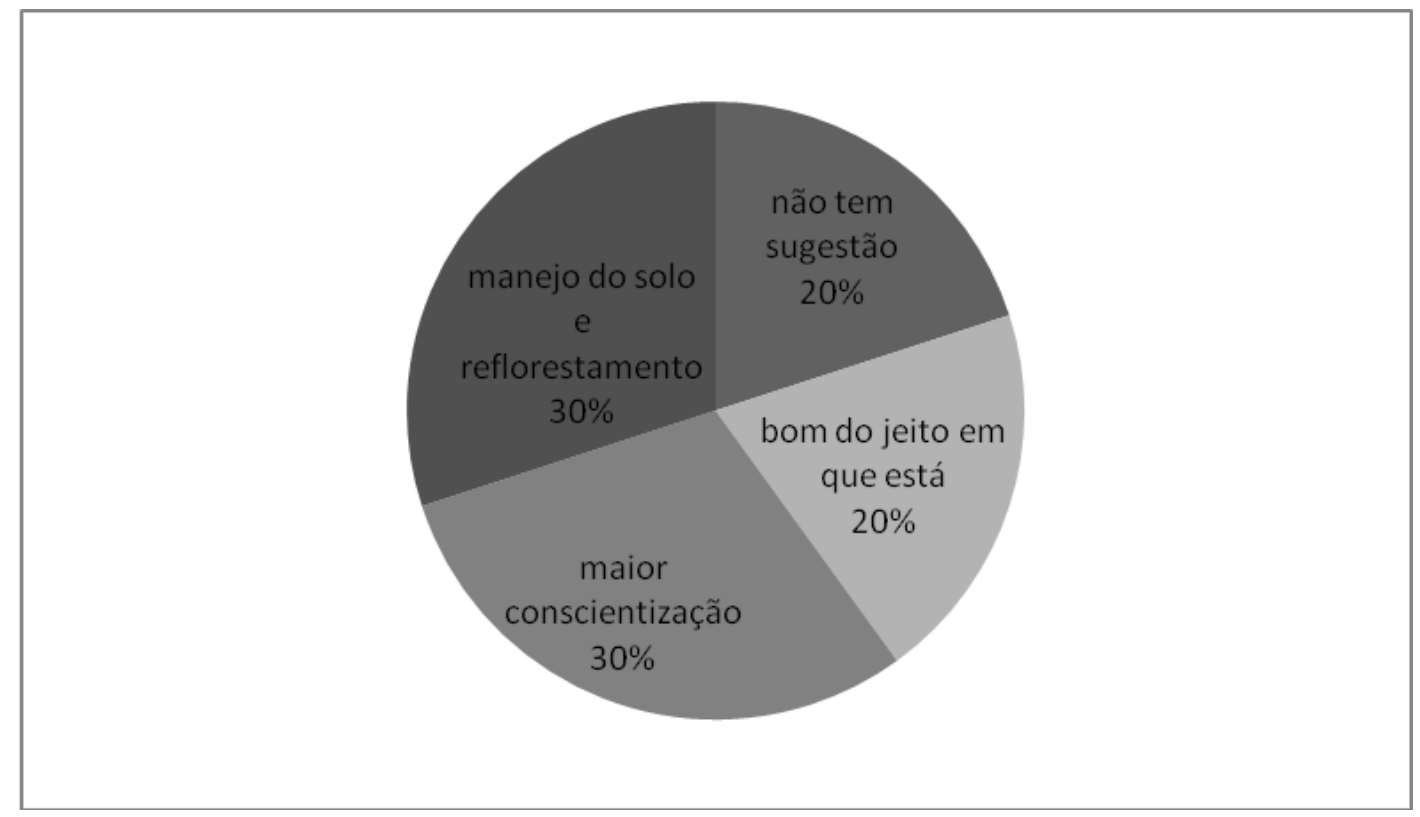

Fonte: Dados da pesquisa (2013). Org. dos autores.

Conforme Agraer (1997) a composição florística nos lotes do assentamento é inexistente, em virtude do desmatamento realizado pelos proprietários anteriores a implantação do assentamento.

\section{CONSIDERAÇÕES FINAIS}

O objetivo desse artigo foi apresentar um diagnóstico referente à estrutura de saneamento ambiental existente no Assentamento de Reforma Agrária Amparo. Também foram verificados possíveis riscos de contaminação do solo e da água na localidade. Essas questões influenciam na qualidade ambiental e, por conseguinte, na saúde e no bem-estar dos moradores.

A falta de uma adequada estrutura sanitária no assentamento gera impacto negativo ao ambiente, contribuindo para ocasionar riscos de contaminação da água e do solo, auxiliando no aparecimento e proliferação de doenças. Nota-se a necessidade de implantação de sistemas de saneamento ambiental, tais como, de tratamento de esgoto doméstico e coleta de resíduos sólidos. Embora as populações rurais tenham o direito a saneamento assegurado em Leis, o meio rural brasileiro ainda encontra-se carente de tais infra-estruturas. Ainda que, seja verificada por meio do Censo do IBGE que houve avanços em relação à disponibilidade de serviços de coleta de lixo, rede geral de esgoto e fossa séptica e à rede geral de abastecimento de água, no período de 2000 a 2010.

\section{REFERÊNCIAS}

AGRAER. Plano de desenvolvimento sócio-econômico do P.A. Amparo. Dourados, 1997 (mimeo).

ARAUJO, G. H. S.; ALMEIDA, J. R.; GUERRA, A. J. T. Gestão ambiental de áreas degradadas. 2 ed. Bertrand Brasil: Rio de Janeiro, 2007.

BATISTA, M. E. M.; SILVA, T. C. O modelo ISA/ JP - indicador de performance para diagnóstico do saneamento ambiental urbano. Engenharia Sanitária e Ambiental, v.11, n.1, p. 55-64, mar. 2006. DOI: http:// dx.doi.org/10.1590/S1413-41522006000100008

BRASIL. Lei no 8.171, de 17 de janeiro de 1991 . Dispõe sobre a política agrícola, 1991.

BRASIL. Manual de saneamento. 3 ed. rev. Brasília: Fundação Nacional de Saúde, 2006. 
BRASIL. Lei $n^{o} 11.445$, de 5 de janeiro de 2007. Estabelece diretrizes nacionais para o saneamento básico; altera as Leis $\mathrm{n}^{\text {os }} 6.766$, de 19 de dezembro de $1979,8.036$, de 11 de maio de 1990, 8.666, de 21 de junho de 1993, 8.987, de 13 de fevereiro de 1995; revoga a Lei $\mathrm{n}^{\circ} 6.528$, de 11 de maio de 1978; e dá outras providências, 2007.

BRASIL. Ministério do Planejamento, Orçamento e Gestão. Instituto Brasileiro de Geografia e Estatística - IBGE. Censo Demográfico 2010: Características da população e dos domicílios resultados do universo. Rio de Janeiro, 2011. Disponível em:

$<$ http://biblioteca.ibge.gov.br/visualizacao/periodicos/93/ cd_2010_caracteristicas_populacao_domicilios.pdf $>$. Acesso em: 13 fev. 2012.

DALTRO FILHO, J.; SANTOS, D. C. G. Avaliação das condições de saneamento num Assentamento do INCRA em Sergipe. In: CONGRESSO BRASILEIRO DE ENGENHARIA SANITÁRIA E AMBIENTAL, 21, 2001a, João Pessoa. Anais eletrônicos... Disponível em: <http://www.bvsde.paho.org/bvsaidis/brasil21/ vii-002.pdf $>$. Acesso em: 10 fev. 2013.

DALTRO FILHO, J.; SANTOS, D. C. G. Soluções alternativas de saneamento ambiental para um assentamento do INCRA em Sergipe. In: CONGRESSO BRASILEIRO DE ENGENHARIA SANITÁRIA E AMBIENTAL, 21, 2001b, João Pessoa. Anais eletrônicos... Disponível em: $<$ http://www.bvsde.paho.org/ bvsaidis/brasil21/vii-003.pdf $>$. Acesso em: 10 fev. 2013.

ERMENEGILDO, L. F. S. et al. Vazão específica e precipitação média na bacia do Ivinhema. Revista Agrarian, nota técnica, v.5, n.18, p.428-432, 2012.

FERRETE, J. A. et al. Risco de contaminação ambiental por esgotos domésticos e resíduos sólidos em lotes do assentamento de reforma agrária Ezequias dos Reis, município de Araguari (MG). In: CONGRESSO BRASILEIRO DE ENGENHARIA SANITÁRIA E AMBIENTAL, 24, 2007, Belo Horizonte. Anais... Belo Horizonte, 2007.
FERRETE, J. A. et al. Qualidade ambiental da área do projeto de assentamento Ezequias dos Reis (Araguari, MG). Horizonte Científico. Uberlândia, v. 1, p. 1-28, 2008.

INCRA (Instituto Nacional de Colonização e Reforma Agrária). Mapa do Assentamento Amparo. Dourados, 1997.

INCRA (Instituto Nacional de Colonização e Reforma Agrária). Números da reforma agrária. 2012. Disponível em: < http://www.incra.gov.br/index.php/ reforma-agraria-2/questao-agraria/numeros-da-reformaagraria $>$. Acesso em: 18 out. 2012.

IBGE (Instituto Brasileiro de Geografia e Estatística). IBGE Cidades. Disponível em: < http://cidades.ibge. gov.br/xtras/home.php > Acesso em: 10 mar. 2014.

IORIO, S. M. et al. A perspectiva da educação ambiental e o processo histórico do saneamento básico: a instalação das redes de água e esgoto nos municípios de Campo Grande/MS e Dourados/MS. Interações. Campo Grande, v.10, n.1, pp. 63-72, jan./jun. 2009. DOI: http://dx.doi.org/10.1590/S151870122009000100007

LOPES, K. C. S. A.; BORGES, J. R. P.; LOPES, P. R.. Condições de vida e qualidade do saneamento ambiental rural como fator para o desenvolvimento de práticas agroecológicas. Revista Brasileira de Agroecologia, v. 7, n.1, p.39-50, 2012.

MOSCARDI, J. P.; NOBRE, M. F. O saneamento ambiental nos assentamentos rurais: o caso do município de Areia Branca - RN. In: CONGRESSO BRASILEIRO DE GESTÃO AMBIENTAL, 3, 2012, Goiânia. Anais eletrônicos... Disponível em: $<$ http:// www.ibeas.org.br/congresso/Trabalhos2012/IX-008.pdf>. Acesso em: 10 fev. 2013.

NOVAES, A. P. et al. A utilização de uma fossa séptica biodigestora para a melhoria do saneamento rural e desenvolvimento da agricultura orgânica. Comunicado Técnico 46, EMBRAPA, 2002. 